\title{
Investigation on E-Learning Adoption Intention Among Chinese Undergraduates Via Innovation Adoption Theory
}

\author{
Zetian Fu, Xiaoshuan Zhang, Weisong Mu, Lingxian Zhang*, \\ and Yajie Gao \\ College of Information \& Electrical Engineering, China Agricultural University, \\ Beijing, China \\ zlx131@163.com
}

\begin{abstract}
E-learning, as an innovative and alternative way of distance learning, provides a strong challenge to the traditional learning with its unique advantage. The paper, for the diffusion of e-learning adoption in China, investigates people's perceptions and attitudes toward adopting e-learning, and explores the factors affecting the e-learning adoption behavior from innovation adoption perspective. Based on the model of Rogers' innovation adoption theory, the factors in each of "perceived innovative attributes" that affect the individual adoption behavior will be analyzed to test the relationship between these attributes and e-learning adoption. The result shows that the four perceived innovative attributes, namely "perceived relative advantage", "perceived compatibility", "perceived trialability" and "percieved observability", have certain influences on peoples' adoption of elearning.
\end{abstract}

Keywords: Adoption intention; E-Learning; Adoption behavior; Perceived innovation attributes; Innovation adoption theory; China.

\section{Introduction}

E-learning can offer potential learners an alternative and innovative learning environment compared with the traditional learning [1]. As e-learning is still a new concept for many people, their attitudes towards its application have not been fully studied, especially in China [2]. It is believed that a better understanding of e-learning adoption behavior would enable e-learning providers to offer courses more likely accepted by future e-learners [1]. The innovation diffusion theory developed by Rogers, is clarified five perceived attributes of the innovation, and has the influence on the innovation adoption [3]. Based on extensive study on many different innovations, the theory provides the basic model of how perceived attributes affect the adoption of innovation. In the original framework proposed of Rogers, the adoption of innovation was regarded as the dependent variable. Without breaking the consistency of the original framework, some researchers had regarded the adoption of the

\footnotetext{
${ }^{*}$ Corresponding author.
} 
innovation as the dependent variable instead [4]. It appears that the importance of issues related to the adoption of e-learning in China has not been fully recognized [2]. No previous studies have been conducted to analyze the perceptions of e-learning adopters and e-learning adoption intention of non-adopters in China [2] [5]. Thus, this research tries to explore the acceptance and intention of e-learning in China based on the model of Rogers' innovation adoption theory.

\section{Methodology}

\subsection{Theoretical Framework of Assessment Method}

Rogers has identified five attributes of an innovation that are key influencers on innovation acceptance. According to Rogers, these characteristics include relative advantage, compatibility, complexity, trialability, and observability [3]. This research will try to explore what the relationships between perceived attributes and the adoption intention of e-learning by Chinese undergraduates as a case. The theoretical framework of the paper regards five perceived innovation characteristics above as independent variables, and the e-learning adoption intention as a dependent variable whether or not to have influence on the e-learning adoption intention.

\subsection{Research Hypothesis}

Based on Rogers's original model, the research hypotheses are as followings. Hypothesis I: Higher level of perceived relative advantage will positively affect the level of the intention of e-learning adoption (LIEA).

Hypothesis II: Higher level of perceived compatibility will positively affect LIEA. Hypothesis III: Higher level of perceived complexity will negatively affect LIEA. Hypothesis IV: Higher level of perceived trialability will positively affect LIEA. Hypothesis V: Higher level of perceived observability will positively affect LIEA.

\section{Results and Discussion}

A total of 154 questionnaires are distributed and collected, 134 of which are valid responses. All valid respondents said they had not ever obtained a formal qualification through an e-learning course in the past or are currently engaged in an e-learning course. 97 percent of respondents are between 18 and 22, and only 3 percent between 23 and 25. Similarly, all respondents are full-time undergraduates.

\subsection{Respondents' Perception on Innovative Attributes}

With regard to the questions on each of the five components of the theoretical framework, the respondents were asked their opinions on various statements. In order to analyze the respondents' information, the scales of answers are coded and divided into five groups of Strongly Agree (5), Agree (4), Uncertain (3), Disagree (2), and Strongly Disagree (SD, 1). 
As a result, there is not more difference between the individual answers in each of the eleven questions. The highly perceived relative advantage of e-learning is "pricing, flexibility, personal control, access (time) and access (place)" (around 4). $\mathrm{SD}$ in compatibility indicates that there are not more differences (around 3 except question 7). Students have generally a higher level perception on the complexity of elearning adoption except "access to technology". Perceptions on trialability are quite high comparing other innovative attributes(above 3.50). Except "opportunities to observe other e-learners experiences", the other three questions are between 3.10 and 3.34 .

\subsection{Summary of Respondents' Perception vs. Intention}

Analyzing table 1 horizontally, the value points on relative advantage, compatibility, trialability and observability are all descending with the decrease of intention degrees. That is the same situation as the hypothesis above that the higher perception of relative advantage, compatibility, trialabililty and observability be, the higher level of intention on adopting e-learning be. However, except complexity, respondents who are unlikely or very unlikely to try e-learning have similar levels of perceived complexity as these who choose "likely" or "very likely", as indicates that complexity hypothesis in Roger's theory is not true in China's case.

Table 1. A summary of respondents' perceptions from different e-learning intention groups

\begin{tabular}{lllllllllll}
\hline Variables & \multicolumn{2}{c}{$\begin{array}{c}\text { Very likely } \\
(9)\end{array}$} & \multicolumn{2}{c}{$\begin{array}{c}\text { Likely } \\
(24)\end{array}$} & \multicolumn{2}{c}{$\begin{array}{c}\text { Not sure } \\
(35)\end{array}$} & \multicolumn{2}{c}{$\begin{array}{c}\text { Unlikely } \\
(46)\end{array}$} & \multicolumn{2}{c}{$\begin{array}{c}\text { Very unlikely } \\
(20)\end{array}$} \\
\cline { 2 - 11 } & Mean & SD & Mean & SD & Mean & SD & Mean & SD & Mean & SD \\
\hline Relative & 3.89 & 0.41 & 3.68 & 0.44 & 3.41 & 0.42 & 3.26 & 0.56 & 2.83 & 0.60 \\
Advantage & & & & & & & & & & \\
Compatibility & 3.44 & 0.51 & 3.33 & 0.53 & 3.26 & 0.43 & 3.01 & 0.43 & 2.76 & 0.59 \\
Complexity & 3.37 & 0.42 & 3.33 & 0.68 & 3.31 & 0.54 & 3.40 & 0.47 & 3.36 & 0.78 \\
Trialability & 4.22 & 0.52 & 3.64 & 0.68 & 3.55 & 0.67 & 3.51 & 0.61 & 3.29 & 0.59 \\
Observability & 3.83 & 0.71 & 3.32 & 0.65 & 3.20 & 0.67 & 2.95 & 0.57 & 2.75 & 0.47 \\
\hline
\end{tabular}

\subsection{Hypothesis Tests}

Collecting required information from respondents to test research hypotheses, the correlation analysis has been conducted by the relationships established between respondents' intention to adopt e-learning and their perceptions on different innovation attributes (Table 2). Hypothesis I is accepted. The results show that the level of intention to adopt e-learning is significantly related to the perceived relative advantage. It suggests that the higher the perceived level of relative advantage over traditional learning, the more likely students would adopt e-learning method. Hypothesis II is accepted. According to the correlation analysis, perceived compatibility is found to have significant positive influence on e-learning adoption. Hypothesis III is rejected (not significant). The results show that the perceived complexity of e-learning has no significant negative influence on students' adoption intention, as seems inconsistent with previous studies on innovation adoptions. 
Hypothesis IV is accepted. There is significant positive relationship between perceived trialability and e-learning adoption. Hypothesis V is accepted. The more visible the results of an innovation, the more likely the innovation will be adopted. To Chinese students, whether they are aware of benefits and advantages demonstrated by other e-learners will affect their adoption decisions.

Table 2. The correlation analysis between the intention to adopt e-learning and five innovation

\begin{tabular}{llll}
\hline Variables & Mean & Correlation Coefficient & Significance \\
\hline Relative advantage & 3.351 & $0.491^{* *}$ & 0.000 \\
Compatibility & 3.124 & $0.389^{* *}$ & 0.000 \\
Complexity & 3.354 & -0.031 & 0.362 \\
Trialability & 3.558 & $0.270^{* *}$ & 0.001 \\
Observability & 3.110 & $0.401^{* *}$ & 0.000 \\
\hline
\end{tabular}

Note: ** Is significant at $\mathrm{P}<0.01$.

\section{Conclusion}

The study suggests that Rogers' innovation adoption theory provide useful framework to examine e-learning acceptance behavior as a case. Findings help to gain valuable insights into the factors of e-learning adoption decision and how e-learning benefits perceived affect adoption intention. However, the paper has certain limitations due to its sample selection, sample size and respondents profile; Moreover, using crosssectional survey, the changes of perception in a long term could be ignored.

Acknowledgments. We acknowledge financial support from the Ministry of Science \& Technology of China (2006037035012), and Beijing Municipal Science \& Technology Commission (Dr. Thesis Support Project ZZ0521).

\section{References}

1. S.S. Liaw, H. M. Huang, G. D. Chen. An activity-theoretical approach to investigate learners' factors toward e-learning systems. Computers in Human Behavior (2006) (in press)

2. van Raaij, E.M., Schepers, J.J.L.. The acceptance and use of a virtual learning environment in China. Computers \& Education (2006) (in press)

3. Rogers M. E.: Diffusion of Innovations, New York: The Free Press (1995)

4. Agarwal, R., Prasad, J.:"The Role of Innovation Characteristics and Perceived Voluntariness in the Acceptance of Information Technologies", Decision Sciences, Vol. 28, No. 3(1997) 557-582

5. Yajie Gao: A Study of E-learning Adoption and Diffusion in Higher Education in China. China Agricultural University, 2004 